\title{
Research on Innovative Practice of Civil Engineering Construction Technology
}

\author{
Li Hai-chao ${ }^{1}$ \\ ${ }^{1}$ School of Management,300191, Tianjin University of Technology, Tianjin, China
}

\begin{abstract}
Nowadays, my country's economy is developing faster and faster, people's living conditions are gradually improving, and people's requirements for the quality of life are also improving. Housing is a place where people often come and go. The quality of housing is related to people's daily life safety and also affects economic development. Therefore, the construction industry should pay attention to the improvement of the quality of housing and provide people with high-quality housing construction. For civil engineering, on the basis of ensuring the quality, the construction unit needs to fully consider the economic benefits, so that the construction unit can achieve quality and cost reduction. In order to ensure that the quality of civil engineering meets the standards proposed by the country, the construction unit needs to plan the details of the building in detail during the construction process and adopt standardized construction techniques. Therefore, this article will conduct an in-depth analysis on the innovation of civil engineering construction technology, so as to facilitate the reference of relevant construction units.
\end{abstract}

\section{Research and analysis on current civil engineering construction technology}

\subsection{Features}

Research shows that the current civil engineering construction in my country has the following characteristics: fixity, fluidity, gradual change, integrity, and complexity. The following is an analysis of the five characteristics of civil engineering construction technology.

\subsubsection{Fixed}

In a real civil engineering construction project, the construction unit must ensure that the project has good stability before starting other links of construction. Otherwise, once a collapse occurs during the construction process, not only the lives of the construction personnel will be affected, but the construction The unit will also lose a large amount of construction funds and need to reconstruct the civil engineering. Therefore, in the process of adopting construction technology, the types of construction technology should be analyzed, and it is necessary to be able to choose construction technology with strong fixedness, so that it can improve the stability of civil engineering in the process of application, and the construction technology itself It has a certain degree of stability and can also provide a good foundation for the construction stability of civil engineering. Generally, this kind of construction technology with strong fixedness will be widely used in the construction process of civil engineering [1].

\subsubsection{Liquidity}

In the process of civil engineering construction, the participation of construction personnel is bound to be required. Construction personnel need to understand the construction environment, analyze the application method of construction technology, and operate related construction instruments. In this way, the construction site will have a certain degree of fluidity. Generally, after completing the design of the construction plan, the designer will put forward the requirements of safe construction and standard construction to the construction personnel. However, due to the fluidity of the construction site, there are also unknown changes in the construction situation, which requires relevant technology Managers must do a good job in the supervision of the application of construction technology to avoid problems that are not properly resolved when they occur.

\subsubsection{Gradual}

The continuous updating of science and technology and the change of people's ideas and concepts all show that this era is constantly developing, and civil engineering construction exists as a long-term project in this society. For changes in construction technology, the construction industry should also pay attention to it. The construction industry needs to integrate with the times. According to the changing real needs, the construction technology should be improved, the performance of the construction

\footnotetext{
* Corresponding author: Li Hai-chao 1412983069@qq.com
} 
technology should be improved, and the application efficiency of the technology should be optimized, so that the construction of civil engineering can follow the development of the times and the construction industry will not lag behind in the development of society.

\subsection{Status of application of construction technology}

Although the current construction technology can also play a certain role in the construction quality of civil engineering, its core technical requirements need to be improved. The current construction technology can be improved according to the actual construction plan, so that the construction unit can be more standardized. Use construction technology to improve the quality of civil engineering buildings. And to a certain extent, the new construction technology also meets the needs of the development of the construction industry, creating more benefits for the construction industry. Therefore, the improvement of construction technology needs to be improved. In addition, the current construction technology of civil engineering in our country needs to combine different construction methods in the application process. Therefore, there are often differences between the original construction plan and the original construction plan during the real site construction. This requires the construction unit to deal with it. The continuous improvement of the construction plan can ensure the quality of the civil engineering building. The materials, structure, and environment are also factors that affect the application of construction technology. If the relevant configuration is not done well, the construction technology will not be able to exert good use value. Therefore, it is more important to innovate civil engineering construction technology.

\section{In-depth analysis of construction technology innovation for civil engineering construction}

\subsection{Forming the concept of technological innovation}

improving the mechanism of technological innovation supervision and application. The economy is developing rapidly, and competition among various industries is gradually increasing. As an important part of my country's economic development, the construction industry is an important part of China's economic development, and its development effects affect the improvement of my country's overall economy. Therefore, the construction industry must keep up with the development of the times and form a new development concept. For the construction industry, the most important thing in the development process is the application of construction technology. Effective construction technology can not only create high levels for the construction industry. The economic benefits can also enable it to improve the quality of engineering construction on the basis of reducing costs. Therefore, the construction industry should do a good job in construction technology innovation research, and relevant professional staff should actively participate in the process of construction technology innovation. To form a new concept of technological innovation, the construction industry must also provide sufficient technology costs to ensure that technical innovators can develop newer and better-performing construction technologies. Higherperformance construction technologies will create more for the construction industry. The benefits. At the same time, in the process of technical innovation for construction technology, construction units also need to educate and train construction personnel about the application of new technologies to let them understand the impact of new construction technology on themselves and the entire construction project, such as In the construction of civil engineering, after the concept of new technology application is well publicized, the relevant supervision mechanism shall be clarified to the construction personnel so as to enhance the construction personnel's sense of responsibility. The construction personnel can standardize the operation of the new construction technology, and the quality of the civil engineering will be Guaranteed. In addition, the construction unit should also establish a construction team to improve the quality of every construction worker in the construction team, so that the construction efficiency of civil engineering can be improved by combining the efforts of the construction personnel with the new construction technology.

\subsection{Not afraid of hardships and dangers, boldly innovate construction technology}

There will inevitably be certain risks in the application of new construction technology. Therefore, construction units must be able to form a sense of facing risks, and continue to study and improve in the process of using new technologies to carry out civil engineering construction. It is necessary to ensure the stable operation of the new construction technology on the basis of safe construction, and to solve the problems in time when problems are found, so as to improve the performance of the construction technology. In addition, in practice, it is necessary to consider whether the new construction technology can enhance market competitiveness, and to maintain the core concept of the technology. The new construction technology also needs to pay attention to the impact on the construction environment. Nowadays, my country's environmental pollution is serious. When innovating new construction technology, we must think deeply about whether it is beneficial to the protection of our country's environment. The construction unit must make the new construction technology meet our country's environmental protection. The concept of environmental protection, so that the construction industry can achieve sustainable development when using new construction techniques.

As an important part of civil engineering construction technology, deep foundation pit technology can improve the stability of our country's housing construction in projects that use this technology, so that it has the same seismic performance. Therefore, for the innovation of 
deep foundation pit technology, our country The construction industry should do a good job in related research. In today's world, natural disasters occur frequently. We cannot prevent the damage caused by nature, but we can prevent it. Protecting the environment is one aspect, and it is also the key to our own maintenance.

Therefore, in the process of building houses, it is very important to improve the seismic performance of house construction. The traditional deep foundation pit technology can only be used with buildings on the ground, and the stability is not good. In the event of an earthquake disaster, there will still be serious collapses, which poses a danger to people's lives. For the research of new deep foundation pit technology, technical researchers can integrate its pile-anchor supporting system into it, which can be used in underground construction and can also enhance the quality of civil engineering construction, especially for construction sites with poor environment. This kind of technology can reduce the construction risk, because in the construction site with poor environment, the construction personnel can use the two aspects of the cast-in-place pile and the pre-stressed anchor to control the construction process to a certain extent, so that the quality of the cast-in-place pile can be controlled. A certain guarantee can also prevent the frequent occurrence of civil engineering quality problems.The stress innovation technology is shown in the figure below:

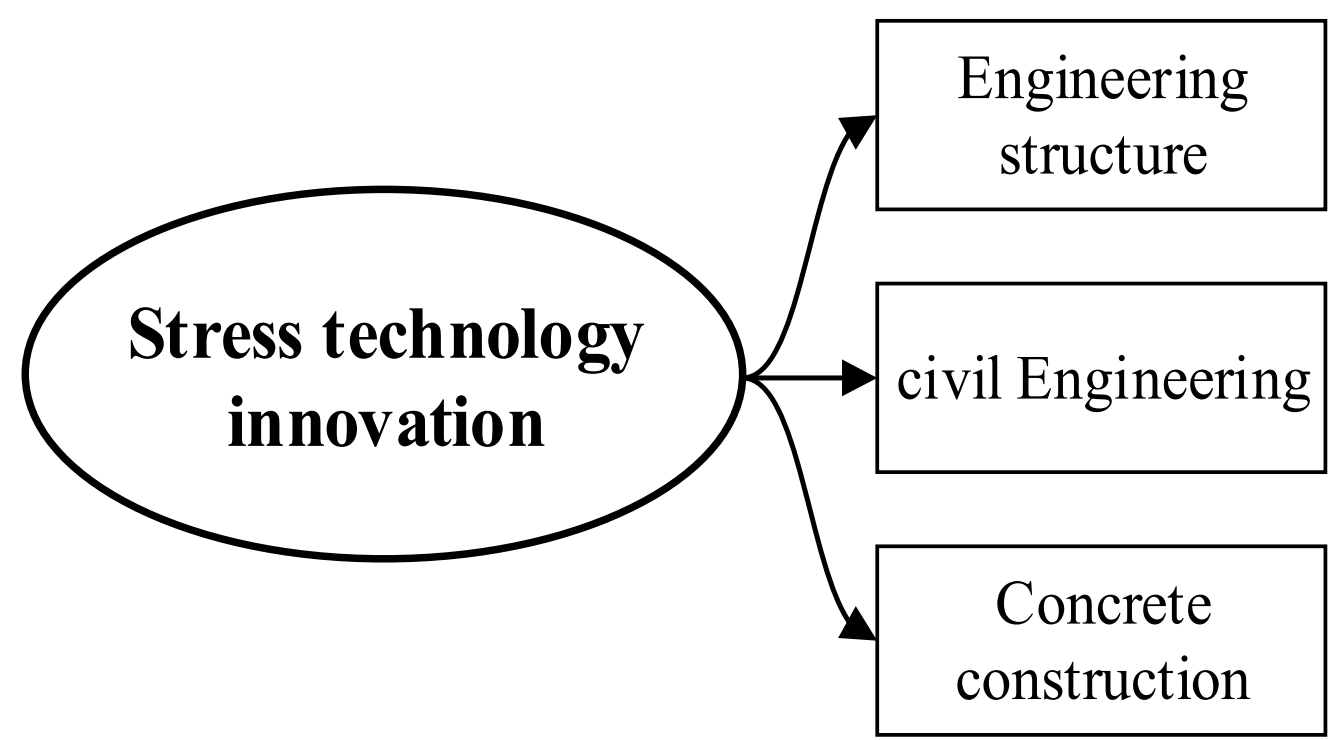

Fig. 1. The stress innovation technology.

\section{Concluding remarks}

In short, for the innovation of civil engineering construction technology, it is necessary to combine the actual development of my country's construction industry, research more effective technology based on the current more effective construction technology of my country's construction industry, and make its technology more advanced with the help of advanced scientific knowledge. It is novel and has certain application value. In the process of innovation, researchers must promptly change the traditional concept of technological creation, according to the real needs of the construction industry, improve the construction technology innovation plan, establish a sound mechanism for the use of new construction technology, and ensure that the innovative construction technology can be used. To improve the quality of civil engineering construction. When using the new construction design, the construction unit must be able to actively implement it and make it the core of the project construction. In this way, construction personnel can operate correctly and construction units can use new construction techniques to increase the cost of civil engineering and reduce economic costs.

\section{References}

1. Sun Zhuozhen,Du an Xiaohong, Zhang Chunhua. Analyze the innovative practice research of civil engineering construction technology [J]. Architectural Engineering Technology and Design, 2018 (14): 12.

2. Dong Taotao. Analyze the innovative practice research of civil engineering construction technology [J]. Consumer Guide, 2017 (35): 134-156.

3. Li Jing. Analyze the innovative practice research of civil engineering construction technology [J]. Decoration World, 2018 (2): 25-47.

4. Li Wenzheng. Analysis of the current situation of civil engineering construction management and optimization countermeasures $[\mathrm{J}]$. Sichuan Cement, 2017, (10): 137-138. [5] Li Xiaojun. Research on construction technology and innovation of civil engineering construction [J]. Sichuan Cement, 2017, (10): 120-121.

5. Xu Xiaoqing. Research on how to strengthen the current civil engineering construction management [J]. Building Materials and Decoration, 2017, (44): 86-87. 
6. Wu Yuanzheng. Discussion on concrete structure problems and countermeasures in civil engineering construction $[\mathrm{J}]$. Housing and Real Estate, 2019, (19): 124-125.

7. Jiang Fuhai. Research on the innovation of civil engineering construction technology $[\mathrm{J}]$. Doors and windows, 2019, (13):77-78.

8. Ning Bin. Analysis of Civil Engineering Construction Technology [J]. Jiangxi Building Materials, 2017, (14): 107-108. 